\title{
The acqusition and extinction of instrumentally conditioned approach behavior in the tiger salamander (ambystoma tigrinum)
}

STEPHEN F. DAVIS ${ }^{1}$ ANO JAY J. SINGER SOUTHERN METHODIST UNIVERSITY

Instrumental appetitive conditioning was studied in the tiger salamander, Ambystoma tigrinum. Ss were trained to snap at a manipulandum in order to obtain food reward. The results showed that the Ss were capable of learning the task and that extinction returned the instrumentally conditioned response to the operant level.

Early investigations (Copeland, 1913; Kuntz \& Zozaya, 1922) on the feeding behavior of salamanders and newts have demonstrated that approach behavior to food objects is elicited by visual stimulation. Snapping behavior that is directed to stationary food objects appears to be a function of the odor cues of the objects. Other investigations (Burr, 1916; Nicholas, 1922) confirmed and extended these results by showing that animals with ablated olfactory end organs will snap at visual stimuli, and that blind animals will snap at stationary odorous objects.

More recently, Goldstein (1960) has shown that the common water salamander, Triturus viridescens, possesses a hunger drive similar to that shown by mammals, but that a deprivation period of at least four days is required before the effects of the drive can be demonstrated. Goldstein's research also showed that there were no differences in gross motor activity under different levels of deprivation $(4,8,16$, and 32 days).

Vernon \& Butsch (1957) investigated instrumental aversive conditioning in salamanders with normal brain cell size and salamanders with enlarged brain cell size. The results showed that both groups of Ss were capable of learning the task of traversing a maze to avoid the punishments of continuous prodding and bright light, although the normal Ss were superior learners.

The study to be reported was concerned with conditioning instrumental approach behavior in the tiger salamander (Ambystoma tigrinum), as well as with whether or not a typical form of instrumentally conditioned behavior could be obtained from a salamander without undue concern for drive states.

\section{Procedure}

The Ss were five adult tiger salamanders purchased from a commercial biological supply house. The Ss were housed in individual 7 gallon aquariums having a coarse sand floor approximately $1 / 2 \mathrm{in}$. thick. Water in the aquarium was kept approximately $1 / 4$ in. above the level of the sand.
Since a pamphlet on the feeding of aquarium animals prepared by the General Biological Supply House of Chicago mentioned that the tiger salamander was a voracious eater, It was felt that if an "attractive" enough reinforcer was used, learning could proceed in an orderly fashion without any undue concern over instating and maintaining a hunger drive. During the observation period that preceded the experiment, the Ss were presented with a variety of foods (canned dog food, earthworms, raw hamburger, and chopped steak) in an attempt to find the most "preferred" food, determined by quickness of approach and snapping behavior. All Ss preferred the raw chopped steak, so it was selected to be the reward during the experiment. The daily ration for each $\mathrm{S}$.consisted of a $1 / 4$ g piece of raw chopped steak, which was always presented to the Ss via a pair of 12 in. forceps.

Snapping was chosen as the operant response because of ease of observation and relatively high operant level. A snap was defined as a visible opening and closing of the mouth that was directed toward the manipulandum.

The manipulandum used was a 2 in. circular blue plastic disc with a $3 / 4$ in. high conical projection in the center. Both the manipulandum and reward were manually presented to the Ss.

The experiment began with the Initial presentations (three trials, one per day) of the manipulandum to determine the operant level. Then followed a six day shaping period during which the manipulandum and food were presented (two trials per day). On the first two days the presentation of food and manipulandum was simultaneous, whereas on subsequent days the time interval between the presentation of food and manipulandum was gradually lengthened until, on the final day, the $\mathrm{Ss}$ were required to snap at the manipulandum in order to obtain their daily ration of food. These final two trials of the shaping period were not operationally different from acquisition trials.

Acquisition consisted of 10 trials (one per day), and was immediately followed by 15 extinction trials (one per day). On trials to determine the operant level and during extinction the $\mathrm{Ss}$ were fed $30 \mathrm{~min}$ after the completion of the last trial of the daily session. For all experimental sessions the daily order for administering trials to Ss was randomly determined. A trial was completed and the manipulandum removed if a $\mathrm{S}$ failed to snap within $30 \mathrm{sec}$. No-response trials 
Table 1. Individual and Mean Latencies in sec

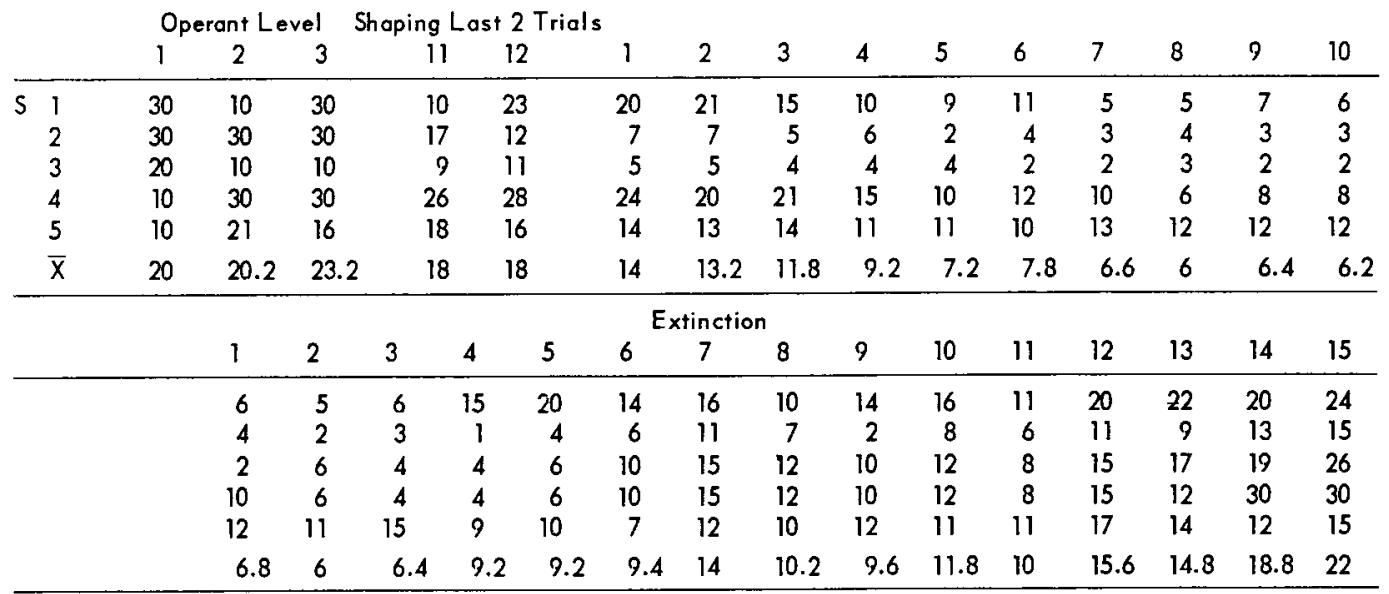

were assigned a value of $30 \mathrm{sec}$, and this value was used in statistical treatments.

\section{Results}

The individual and mean latencies of snapping for all phases of the experiment are presented in Table 1.

Using $t$ tests (one-tailed) for correlated samples, several comparisons were made with the following results. The difference between acquisition Trials 1 and 10 was significant $(t=2.64$, $d f=4, p<.05)$, indicating that latencies at the beginning of acquisition were significantly longer than those observed at the end of acquisition. Comparisons between acquisition Trial 10 and extinction Trial 15, and between extinction Trial 1 and extinction Trial 15 were both significant $(t=-4.12, d f=4, p<.01$; and $t=-4.10, d f=4$, $p<.01$, respectively), while comparisons between the three operant levels and extinction Trial 15 yielded no significant results $(t=-.17, t=-.30$, and $t=.20$, respectively), indicating that the instrumentally conditioned response had undergone extinction, and was returned to a level similar to that observed at the operant levels.

As can be seen, all Ss, with possibly one exception, proceeded to condition and extinguish in a predictable fashion. The one possible exception, $S$ 5, appears to have been a $S$ that was incapable of learning the required task. Due to the fact that $S 5$ died, for no apparent reason, shortly after the experiment, the possibility exists that this $S$ was sick during the experiment and thus hindered in its ability to perform. In accordance with the assumption that the sample of Ss being used was homogeneous, no significance tests were performed on data that excluded S 5. However, it would appear that the results would have been more conclusive had the data for $S 5$ been eliminated from the analysis.

\section{Discussion}

The foregoing results show that the tiger salamander is capable of learning an instrumentally conditioned appetitive response, such as snapping at a manipulandum, and that this response can, in turn, undergo extinction. Although the results strongly indicate that the instrumental response was learned and subsequently extinguished, the authors recognize the possibility of pseudoconditioning. A subsequent replication of this work, therefore, should include presentation of a nonreward manipulandum in order to determine whether or not the increase in performance observed during acquisition was due to learning or simply increased activity. It would appear that advantages such as low cost, ease of maintenance, a voracious appetite, a high level of activity for an amphibian, and a minimum concern for drive states, make the tiger salamander an excellent laboratory animal for comparative learning studies.

\section{References}

Burr, H. S. The effects of the removal of the nasal pits in Amblystoma embryos. J. exp. Zool., 1916, 20, 27-57.

Copeland, $M$. The olfactory reactions of the spotted newt. Diemyctylus viridescens (Rafinesque). J. Anim. Behav., 1913, 3, 260-273.

Goldstein, A. C. Starvation and food-related behavior in a poikilotherm, the salamander, triturus viridescens. J. comp. physiol. Psychol., 1960, 53, 144-150.

Kuntz, A., \& Zozaya, J. The feeding reactions of Amblystoma tigrinum (Green). Stud. nat. Hist. I. a. Univ., 1922-1924, 10 , no. 2, 51-60.

Nicholas, J. S. The reactions of Amblystoma tigrinum to olfactory stimuli. J. exp. Zool., 1922, 35, 257-281.

Vemon, J. A., \& Butsch, J. Effect of tetraploidy on learning and retention in the salamander. Science, 1957, 125, 1033-1034.

\section{Notes}

1. Present address: Department of Psychology, Texas Christian University. 